\title{
The Impact of Injuries on Patients with Epilepsy
}

\author{
Rizaldy Taslim Pinzon ${ }^{1 *}$, Rosa De Lima Renita Sanyasi², Andre Dharmawan Wijono ${ }^{3}$, Fransiscus \\ Buwana $^{3}$, and Jesisca ${ }^{3}$ \\ ${ }^{1}$ Faculty of Medicine, Duta Wacana Christian University, Indonesia
}

${ }^{2}$ Internship Doctor at dr. Efram Harsana Air Force Hospital, Indonesia

${ }^{3}$ Alumnus of Faculty of Medicine Duta Wacana Christian University, Indonesia

*Corresponding author: Rizaldy Taslim Pinzon, Faculty of Medicine, Duta Wacana

Received Date: November 05, 2018

Christian University Bethesda Hospital, Indonesia.

Published Date: December 06, 2018

\begin{abstract}
Background: Epilepsy affects the individual's physical and psychosocial life. People with epilepsy are more prone to physical injury. The incidence of physical injuries has impact on the life of people with epilepsy and it is worsening quality of life (QoL). Identification of predictors for QoL enables comprehensive and effective care.

Objective: This study aimed to knowing the correlation between physical injuries and QoL in patient with epilepsy.

Methods: This study was a cross sectional study. The data is primary data from questionaire filled by patients and medical record at Bethesda Hospital, Yogyakarta. The QoL of epilepsy patients were interviewed using SF-8 questionnaire.

Result: During a total of 29 patients, seizure-related injuries were identified in 10 patients (34,5\%). Most injuries were softtissue injuries (70\%), and the others were accidents (20\%) and burns (10\%). Patients with history of injuries had lower mental health (46.97) but had higher physical health (48.20) than subjects without injuries (mental health 46.99 and Physical health 46.22). Three of those patients (10,3\%) reporting injuries required hospital treatment and they had a lower mental health (42.05) than without hospitalization (mental health 47.55).

Conclusion: Epilepsy had an impact on quality of life. Patients with history of injuries had a lower quality of life score for mental health but higher for physical health.
\end{abstract}

Keywords: Quality of life; People with epilepsy; Injury; Short form 8 health survey

\section{Background}

Epilepsy is a disease characterized by seizures, due to abnormal excessive or synchronous neuronal activity in the brain. Approximately 50 million people worldwide have some form of epilepsy. The estimated incidence of epilepsy was 2.4 million people. In high-income countries, annual new cases are between 30 and 50 per 100000 people in the general population. Some studies in low- and middle-income countries suggest that the proportion is much higher, between 7 and 14 per 1000 people. Close to $80 \%$ of people with epilepsy live in low- and middle-income countries, making it one of the most common neurological diseases globally [1].

In Indonesia there is no definitive data on epilepsy patients, but it is estimated that 1-2 million people suffer from epilepsy. The prevalence of epilepsy in Indonesia was 5 - 10 cases per 1,000 people and the incidence was 50 cases per 100,000 people per year [2]. Epilepsy can be associated with profound physical, psychological, and social consequences and its impact on a person's quality of life (QOL). Patients with epilepsy often have seizures with impairment of consciousness and abnormal uncontrolled movements. Therefore, these patients more prone to risk of injury during their daily activities [3]. A patient with epilepsy can be assessed quality of life based on one factor which is physical injury during epilepsy. Health-related quality of life is a multi-dimensional concept that includes domains related to physical, mental, emotional, and social functioning [4].

The quality of life assessment is influenced by the condition of physical, mental, social, and emotional. Quality oflife (QOL) measures 
have become a vital and often required part of health outcomes appraisal. For populations with chronic disease, measurement of QOL gives a meaningful way to determine the impact of health care when cure is not possible. In Indonesia, however the impact of epilepsy on physical injury is also not well documented, and the limited available evidence revealed that the occurrences of physical injury negatively impact on the quality of life of PWE with a high mortality rate compared to general population. Thus, the main purpose of this study was to assess seizure-related physical injury including type of injury are associated with adverse quality of life in people with epilepsy at the Bethesda Hospital, Yogyakarta. We also aimed to examine the potential association of other demographic for impacting quality of life.

\section{Methods}

\section{Study design, area, and period}

This study was cross sectional study design, conducted at the Neurology Clinic, Bethesda Hospital, Yogyakarta from November 2017 to February 2018. Bethesda Hospital is one of the largest hospital in Yogyakarta, then the data may represent a population.

\section{Participants, sample size determination and sampling procedure}

The subjects of this study amounted to 29 epileptic patients aged $\geq 18$ years who diagnosed epilepsy by neurologist. Exclusion criteria on this research were subject who has severe depression, dementia, and persistent decreased level of consciousness and patient disagree to be respondent. Consecutive random sampling technique was employed to select the participants.

\section{Data collection instruments}

Data were collected by interviewing participants using questionnaires. The quality of life assessed by the sf 8 questionnaire. The SF-8 Health Survey is an 8-item short form designed to provide a Health-Related Quality of Life profile. This questionnaire measures the following eight ordinal items: general health (SF8GH), physical functioning (SF8PF), role physical (SF8RP), bodily pain (SF8BP), vitality (SF8VT), social functioning (SF8SF), mental health (SF8MH), emotional roles (SF8RE). Regression coefficient weights are assigned to each item to produce a physical component score (PCS) and a mental component score (MCS) for each patient. Variable of injury include history of injury, type of injury, and hospitalization due to injury.

\section{Data analysis}

Data analysis include univariate analysis and bivariat analysis. The univariate analysis used to identify the characteristics of subjects. The bivariate analysis was using Mann-Whitney U test and Kruskal-Wallis test to measure the significant factor(s) to influencing QoL.

\section{Ethical consideration}

Ethical approval was obtained from the Medical and Health Research Ethics Committee of the Duta Wacana Christian University School of Medicine (Komisi Etik Penelitian Kedokteran dan Kesehatan Fakulas Kedokteran UKDW) No. 583/C.16/FK/2018. This study used primary data. There was no compulsion to patients to be study subject. The data used only for the purpose of research. Patients identity (name and address) will be classified (Table 1).

\section{Result}

A total of 29 PWE, 14 females (51\%) and 15 males (49\%). It appears that female's quality of life was higher than male both physically and mentally (Table 2). Age of respondents was mostly less than 60 years old (51\%) and their quality of life was higher than people aged over 60 years old (Table $3 \& 4$ ). The statistical test results found that age have significant correlation with mental quality of life with $p$ value $<0.05$. Ten subjects $(34,5 \%)$ reported having injuries during seizure in the past 12 months. Subjects with injuries had lower mental quality of life but had higher physical quality of life than subjects without injuries (Figure 1).

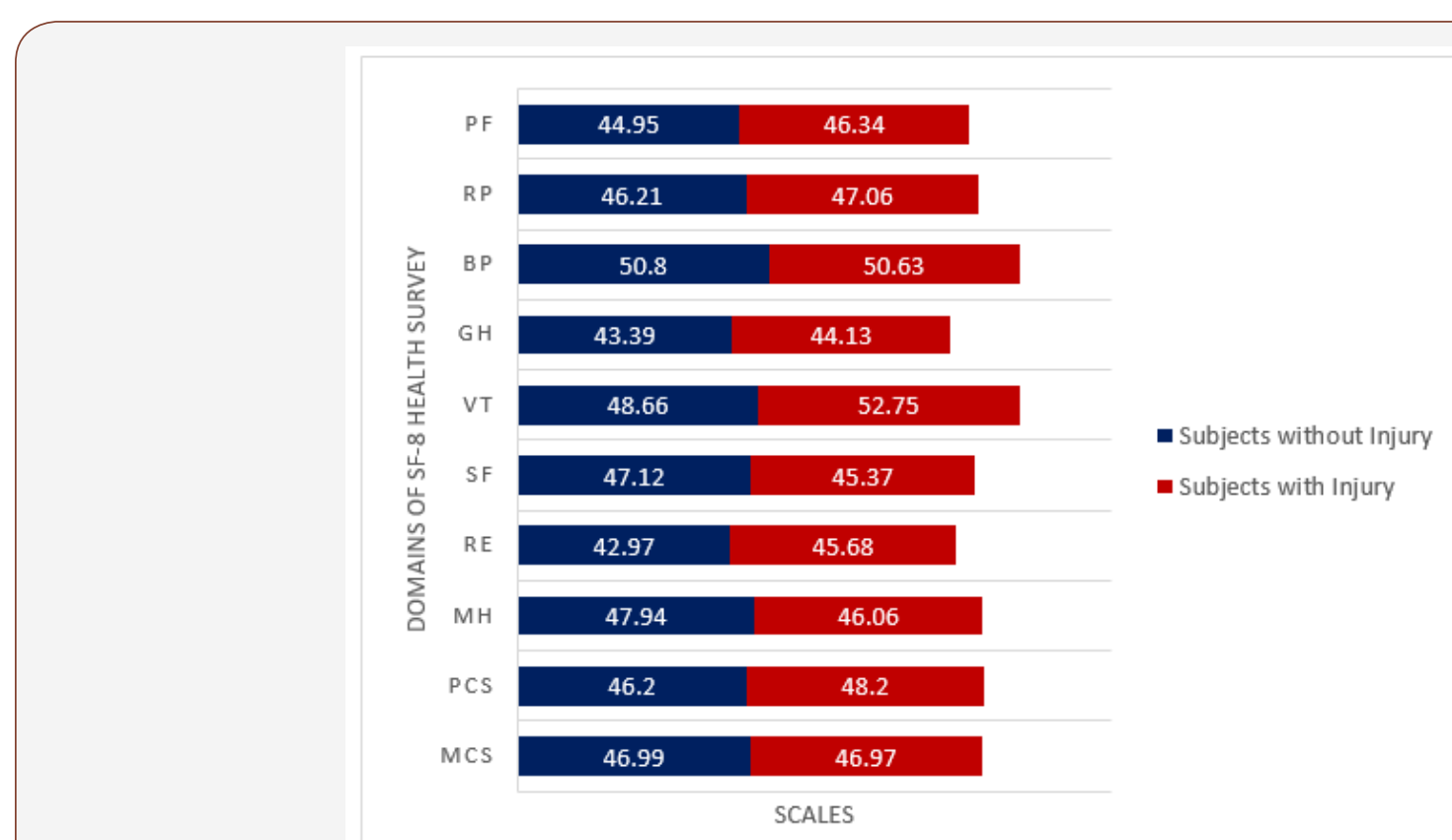

Figure 1: Comparison of the Quality of Life of Patients with Injury and Without Injury. 
Most subjects [7 subjects (24\%)] reported having soft tissue injury. This was followed by motor vehicle accidents [2 subjects $(7 \%)]$ and burn [1 subject (3\%)]. Types of injuries in relation to subject's quality of life are summarized in Table 5. Evidently, subjects with burn injury had a lowest mental quality of life than the other injuries. Among those injuries, 3 subjects $(10 \%)$ need to be hospitalized (Table 6). Overall, statistical analysis showed that there was no significant correlation between gender, history of injury, type of injury, and hospitalized due to injury with the quality of life of people with epilepsy (Tables 1-6).

Table 1: Domains of the SF-8 Health Survey Standard.

\begin{tabular}{|c|c|}
\hline $\begin{array}{c}\text { Sub-scales of SF-8 Health Survey } \\
\text { Standard }\end{array}$ & Summary Measures \\
\hline Physical Functioning (PF) & Physical Health (PCS) \\
\hline Role-Physical (RP) & \\
\hline Bodily Pain (BP) & \\
\hline General Health (GH) & Mental Health (MCS) \\
\hline Vitality (VT) & \\
\hline Social Functioning (SF) & \\
\hline Role-Emotional (RE) & \\
\hline Mental Health (MH) & \\
\hline
\end{tabular}

Table 2: Gender Characteristic of Subjects with Epilepsy, SF-8 Score and the Results of Bivariate Analysis.

\begin{tabular}{|c|c|c|c|}
\hline Gender & Male & Female & P-value \\
\hline $\mathrm{n} \mathrm{( \% )}$ & $15(51 \%)$ & $14(49 \%)$ & \\
\hline $\mathrm{PF}$ & 43,56 & 47,44 & 0.21 \\
\hline $\mathrm{RP}$ & 45,84 & 47,21 & 0.446 \\
\hline $\mathrm{BP}$ & 49,52 & 52,06 & 0.422 \\
\hline $\mathrm{GH}$ & 43,26 & 44,06 & 0.945 \\
\hline $\mathrm{VT}$ & 47,38 & 52,97 & 0.074 \\
\hline $\mathrm{SF}$ & 47,31 & 45,66 & 0.682 \\
\hline $\mathrm{RE}$ & 43,71 & 44,11 & 0.874 \\
\hline $\mathrm{MH}$ & 47,02 & 47,58 & 0.472 \\
\hline $\mathrm{PCS}$ & 45,32 & 48,60 & 0.121 \\
\hline $\mathrm{MCS}$ & 46,68 & 47,31 & 0.743 \\
\hline
\end{tabular}

Table 3: Age Characteristic of Subjects with Epilepsy, SF-8 Score and the Results of Bivariate Analysis.

\begin{tabular}{|c|c|c|c|}
\hline Age & $<\mathbf{6 0}$ y.o & $>\mathbf{6 0}$ y.o & P-value \\
\hline $\mathrm{n} \mathrm{( \% )}$ & $17(51 \%)$ & $12(49 \%)$ & \\
\hline $\mathrm{PF}$ & 47.54 & 42.44 & 0.052 \\
\hline $\mathrm{RP}$ & 47.92 & 44.49 & 0.101 \\
\hline $\mathrm{BP}$ & 52.06 & 48.89 & 0.306 \\
\hline $\mathrm{GH}$ & 46.19 & 40.04 & $0.010^{*}$ \\
\hline $\mathrm{VT}$ & 52.08 & 47.23 & 0.081 \\
\hline $\mathrm{SF}$ & 48.78 & 43.31 & 0.116 \\
\hline $\mathrm{RE}$ & 46.94 & 39.6 & $0.013^{*}$ \\
\hline $\mathrm{MH}$ & 49.97 & 43.5 & $0.046^{*}$ \\
\hline $\mathrm{PCS}$ & 48.76 & 44.27 & 0.069 \\
\hline $\mathrm{MCS}$ & 50.47 & 42.04 & $0.017^{*}$ \\
\hline
\end{tabular}

Table 4: History of injury of Subjects with Epilepsy, SF-8 Score and the Results of Bivariate Analysis.

\begin{tabular}{|c|c|c|c|}
\hline History of Injury & Yes & No & P-value \\
\hline $\mathrm{n}(\%)$ & $10(34 \%)$ & $19(66 \%)$ & \\
\hline PF & 46.34 & 44.95 & 0.792 \\
\hline RP & 47.06 & 46.21 & 0.846 \\
\hline BP & 50.63 & 50.8 & 0.904 \\
\hline GH & 44.13 & 43.39 & 0.575 \\
\hline VT & 52.75 & 48.66 & 0.19 \\
\hline SF & 45.37 & 47.12 & 0.848 \\
\hline RE & 45.68 & 42.97 & 0.223 \\
\hline MH & 46.06 & 47.94 & 0.807 \\
\hline PCS & 48.2 & 46.22 & 0.598 \\
\hline MCS & 46.97 & 46.99 & 0.463 \\
\hline
\end{tabular}

Table 5: Type of Injury of Subjects with Epilepsy, SF-8 Score and the Results of Bivariate Analysis.

\begin{tabular}{|c|c|c|c|c|c|}
\hline $\begin{array}{c}\text { Type of } \\
\text { Injury }\end{array}$ & No Injury & $\begin{array}{c}\text { Soft } \\
\text { Tissue } \\
\text { Injury }\end{array}$ & Burn & Accident & P-value \\
\hline $\mathrm{n}(\%)$ & $\begin{array}{c}19 \\
(65,5 \%)\end{array}$ & $7(24,1 \%)$ & $1(3,5 \%)$ & $2(6,9 \%)$ & \\
\hline PF & 44.95 & 45.85 & 40.07 & 51.19 & 0.716 \\
\hline RP & 46.21 & 46.21 & 46.92 & 50.45 & 0.94 \\
\hline BP & 50.8 & 54.07 & 40.07 & 43.87 & 0.231 \\
\hline GH & 43.39 & 44.22 & 32.56 & 49.63 & 0.206 \\
\hline VT & 48.66 & 54.56 & 55.62 & 44.99 & 0.525 \\
\hline SF & 47.12 & 46.51 & 23.44 & 52.36 & 0.312 \\
\hline RE & 42.97 & 46.1 & 29.25 & 52.42 & 0.097 \\
\hline MH & 47.94 & 47.54 & 21.4 & 53.19 & 0.252 \\
\hline PCS & 46.22 & 48.55 & 46.96 & 47.6 & 0.903 \\
\hline MCS & 46.99 & 49.07 & 20.15 & 53 & 0.201 \\
\hline
\end{tabular}

Table 6: Hospitalization of Subjects with Epilepsy, SF-8 Score and the Results of Bivariate Analysis.

\begin{tabular}{|c|c|c|c|}
\hline Hospitalization & Yes & No & P-value \\
\hline $\mathrm{n}(\%)$ & $3(10.3 \%)$ & $26(89,7 \%)$ & \\
\hline $\mathrm{PF}$ & 47.48 & 45.19 & 0.822 \\
\hline $\mathrm{RP}$ & 49.27 & 46.18 & 0.733 \\
\hline $\mathrm{BP}$ & 42.6 & 51.68 & 0.065 \\
\hline $\mathrm{GH}$ & 43.94 & 43.61 & 0.82 \\
\hline $\mathrm{VT}$ & 48.53 & 50.25 & 0.911 \\
\hline $\mathrm{SF}$ & 42.72 & 46.95 & 0.709 \\
\hline $\mathrm{RE}$ & 44.7 & 43.81 & 0.628 \\
\hline $\mathrm{MH}$ & 42.59 & 47.83 & 0.79 \\
\hline $\mathrm{PCS}$ & 47.38 & 46.85 & 0.83 \\
\hline $\mathrm{MCS}$ & 42.05 & 47.55 & 0.943 \\
\hline
\end{tabular}

\section{Discussion}

Epilepsy is one of the most prevalent and challenging neurologic disorders. The main disturbances, seizures, in patients with epilepsy may appear unexpected and often absolutely change the whole lifestyle even at risk for get injury during seizures, that 
assessment of quality of life of patients with epilepsy is really important [5]. Improving quality of life was recognized as a crucial component of management of patients with epilepsy [6].

This study found that the largest percentage (51\%) of epilepsy subject's gender at Bethesda Hospital, Yogyakarta was female, and they had higher physical and mental quality of life than male. Consistent with previous studies, living with epilepsy appears to create more stress and challenges for male than for female. Social expectations based on gender, in this matter male, is higher in most part of the globe. Male tend to be confronted with more responsibilities such as providing emotional and financial support to their partner and children, mentoring relationships with their colleagues, and coping with other social activities. Therefore, seizure-related factors may have a much stronger impact on the health status of male than that of female [7]

This study shows younger age subjects had higher quality of life and statistically significant correlation with mental quality of life. The reason for this result is difficult to determine. Previous systematic review have demonstrated that the elderly was not shown to negatively impact overall quality of life among the epilepsy population. Although elderly were more likely to have limited physical reserve and report more fatigue and loss of energy, their emotional and social well-being was not necessarily less than that of younger populations with epilepsy [8]. Although a similar study suggests that epilepsy chronicity and age of onset relate to patient's quality of life, another study suggests that the "causes" (e.g., stroke or dementia) of new-onset seizures among the elderly are more devastating to quality of life than epilepsy itself [9]. But these results may be caused by other factors that lead to a higher quality of life in young subjects such as tolerability of AEDs, comorbidity, and duration of epilepsy [10].

It has been argued that people with epilepsy are actually less likely to have an accident than people in the general population, possibly because those with epilepsy are more conscious of safety, therefore they are being less exposed to possible dangers (Sonnen, 1994). Nevertheless, a study demonstrates that people with active epilepsy injured while experiencing seizure during activity [11].

In the present study, injuries sustained during seizures were reported by ten subjects (49\%). People with epilepsy (PWE) are at increased risk for seizure-related injury, and it is reported that PWE also have higher incidences of accidents at home, street, and workplace. People with epilepsy are more likely to die as a result of an accident than non-epileptic patients, and a person with epilepsy has $5 \%$ chance per year of visiting an emergency department due to seizure-related injury [12]. Our findings suggest that quality of life is impacted by injuries, subjects with injuries had lower mental quality of life. A study in Philadelphia, USA, has reported that depression is the major contributor to reduced quality of life in the patients with injury [13].

This finding is consistent with a recent report that depression was the strongest factor associated with poor subjective health and was responsible for an average decrease of quality of life scores [14] Our study show injuries does not affected the physical quality of life, possibly caused by reversible injuries. But there is no evidence to show this hypothesis. Thus, it is important to be evaluated more.
Physical injury are common in patients with epilepsy. In this group almost one quarter of subjects sustained soft tissue injury, followed by motor vehicle accident and burn. In one study in Iran on 264 patients with active epilepsy, 43,6\% having soft tissue injury, and the other injury were fracture, burn, dental injury, head injury, and car accident [3]. Driving is an issue of concern among PWE, as unprovoked seizures while driving undoubtedly puts the patient and the public at risk for accidents and injuries [12].

The population-based epidemiological study of Tellez-Zenteno et al. [15] indicated that persons with epilepsy had a higher frequency of burns than the general population (6.9\% vs. 3.9\%). The majority of burns in epileptic patients occur while carrying out daily routine activities, such as cooking, ironing, blow-drying hair, or bathing [16] Interestingly, the mental quality of life is compromised in burn subjects, which consist of social functioning, emotional role and mental health. Cromes et al. [17] have shown that individuals with burn injuries have difficulties integrating to community both in social and relational aspects due to emotional distress, which is the only strong predictor of quality of life in general population.

Our current study also showed that there were three subjects admitted to hospital due to injury, indicating that they had severe injury, and those needed hospitalized had a lower mental quality of life than those who were not hospitalized. Mahrer-Imhof et al. [18] who also explored hospitalized epilepsy patient found that the patient's worry about the seizures influenced their life. They had had to be hospitalized due to the deterioration of their health, causing them to be on sick leave during that time and eventually jeopardizing the workplace [19]. These concerns were also reported in a most recent study that showed that PWE were preoccupied about maintaining employment or being able to attend educational courses [20]. The impact on quality of life might not be a consequence of seizures or injuries, but rather a result of discrimination and misconception about the epileptic disorder.

Fortunately, the majority of seizure-related injuries are nonfatal, with the most common injuries being burns, fractures, softtissue injuries, and submersion accidents. There are several risk factors that lead to increased risk of injury in general. Seizure type has the highest correlation with increased injury risk. Generalized tonic-clonic seizures, atonic seizures, and complex partial seizures are associated with the highest risk of injury because of the alteration in or loss of consciousness. Patients having at least one seizure a month, and with more than three adverse effects due to antiepileptic drugs are also more likely to sustain an injury due to seizures [21].

Risk of injury in an epileptic patient affects employability, insurance eligibility, and education and recreational opportunities. It is noted that patients with active epilepsy are at increased risk for injury, and therefore is important to keep epilepsy under pharmacological remission in order to reduce the risk of injury to the patient, thereby allowing the patient to enjoy normal occupational and social privileges, and an improved quality of life [22].

\section{Limitations of the Study}

There are limitations in this study that hinder extrapolation of the results to the whole population. The study sample is small 
and hospital-based, hence describing a specific limited population Perhaps in larger and randomized samples of PWE, more significant differences might have been observed and the SF-8 results extrapolated to the general population.

\section{Conclusion and Recommendations}

Epilepsy had an impact on quality of life. Patients with history of injuries had a lower quality of life score for mental aspect. Our current study underlines the need for a balance between monitoring safety precautions for PWE to help avoid injury. Clinicians have an important role to identify and manage depression and anxiety in PWE, helping them to maximise physical, mental and social functioning. This is a pilot study; hence future research is recommended to explore sign and the potential causes of low quality of life for more comprehensive and effective care.

\section{Acknowledgement}

None.

\section{Conflict of Interest}

No conflict of interest.

\section{References}

1. World Health Organization (2018) Rate of epilepsy [cited 2018 Feb 8].

2. Harsono (2008) Buku ajar neurologi klinis. Gajah Mada University Press, Yogyakarta, pp. 119-33.

3. Pooya AAA, Nikseresht A, Yaghoubi E, Nei M (2012) Physical injuries in patients with epilepsy and their associated risk factors. Seizure 21(3): 165-168.

4. Ferrans CE (2005) Definitions and conceptual models of quality of life In: Lipscomb J, Gotay CC, Snyder C, editors. Outcomes assessment in cancer. Cambridge University, Cambridge, England, pp. 14-30.

5. Guekht AB, Mitrokhina TV, Lebedeva AV, Dzugaeva FK, Milchakova LE, et al. (2006) Factors influencing on quality of life in people with epilepsy. Seizure 16(2): 128-133.

6. Privitera M, Ficker DM (2004) Assessment of adverse event and quality of life in epilepsy: design of a new community-based trial. Epilepsy Behav 5(6): 841-846.

7. Yue L, Yu PM, Zhao DH, Wu DY, Zhu GX, et al. (2011) Determinants of quality of life in people with epilepsy and their gender differences. Epilepsy Behav 22(4): 692-696.
8. Baranowski CJ (2018) The quality of life of the elderly with epilepsy: a systematic review. Seizure 60: 190-197.

9. Laccheo I, Ablah E, Heinrichs R, Sadler T, Baade L, et al. (2008) Assessment of quality of life among the elderly with epilepsy. Epilepsy Behav 12(2): 257-261.

10. May TW, Pfäfflin M, Brandt C, Füratsch N, Schmitz B, et al. (2014) Epilepsy in the elderly: restrictions, fears, and quality of life. Acta Neurol Scand 131(3): 176-186.

11. Buck D, Baker GA, Jacoby A, Smith DF, Chadwick DW (1997) Patient's experiences of injury as a result of epilepsy. Epilepsia 38 (4): 439-444.

12. Nguyen R, Zenteno JFT (2009) Injuries in epilepsy: a review of its prevalence, risk factors, type of injuries and prevention. Neurol Int 1(1): e20.

13. Richmond TS, Guo W, Ackerson T, Hollander J, Gracias V, et al. (2014) The effect of post-injury depression on quality of life following minor injury. J Nurs Scholarsh 46(2): 116-124.

14. Friedman DE, Islam S, Ettinger AB (2013) Health-related quality of life among people with epilepsy with mild seizure-related head injuries. Epilepsy \& Behaviour 27: 492-496.

15. Tellez-Zenteno JF, Hunter G, Wiebe S (2008) Injuries in people with selfreported epilepsy: a population-based study. Epilepsia 49(6): 954-961.

16. Josty IC, Narayanan V, Dickson WA (2000) Burns in patients with epilepsy: changes in epidemiology and implications for burn treatment and prevention. Epilepsia 41(4): 453-456.

17. Cromes GF, Hovalanahalli R, Kowalske K, Helm P (2002) Predictors of quality of life as measured by burn specific health scale in person with major burn injury. J Burn Care Rehabil 23: 229-234.

18. Mahrer-Imhof R, Jaggi S, Bonomo A, Hediger H, Eggenschwiler P (2012) Quality of life in adult patients with epilepsy and their family members. Seizure 22(2): 128-135.

19. Fisher RS, Vickrey BG, Gibson P, Hermann B, Penovich P, et al. (2002) The impact of epilepsy from the patient's perpective. II. Views about therapy and health care. Epilepsy Res 41(1): 53-61.

20. Nickel R, Silvado CE, Germiniani FM, Paola Ld, Silveira NL, et al. (2012) Quality of life issues and occupational performance of persons with epilepsy. Arq Neuropsiquiatr 70(2): 140-144.

21. Jarrett 00, Fatunde OJ, Osinusi K, Lagunju IA (2012) Pre-hospital management of febrile seizures in children seen at the university college hospital, ibadan, Nigeria. Ann Ib Postgrad Med 10(2): 6-10.

22. Van den Broek M, Beghi E (2004) Accidents in patients with epilepsy: types, circumstances, and complications: a European cohort study. Epilepsia 45(6): 667-672. 